\title{
Effective ways to test changes of practical intelligence in order to assess unintentional learning in laboratory classes
}

\author{
Mohd Hisam Daud ${ }^{l}$, Zol Bahri Razali ${ }^{{ }^{*},}$, Mohamed Mydin M. Abdul Kader ${ }^{l}$ \\ ${ }^{1}$ Robotics and Automation Technology, Faculty of Engineering Technology, Universiti Malaysia Perlis, 02100 \\ Padang Besar, PERLIS, MALAYSIA
}

\begin{abstract}
Previous research shows that experience or academically called 'practical intelligence' in the field of engineering can be measured through comparing experience to the experts in the field. The expert teaches and shows the students the ways to complete some practical tasks based on their own practical intelligence, which they developed for years and becomes their behaviors. Thus after some or repeated hands-on exercises, the level of students' practical intelligence continuously developed and close to the experiences possesses by the experts. By this way, the level of practical intelligence can be assessed if it is referring to the experts score. A measuring instrument, an 'Automated Engineers Testing Kits' consisted of a partially completed circuit in which a battery provides power for a flash light. This is a semi-completed circuit which requires students to diagnose why the light does not work and complete the necessary connections. The authors hypothesize that practical intelligence measured in the context of constructing simple circuits used for laboratory experiments will be correlated with performance in real constructing tasks on similar complicated electrical circuits. The results show the correlations between the level of practical intelligence and the ability to construct the circuits. The methodology is described in the paper.
\end{abstract}

\section{Laboratory Classes}

Engineering is a practicing profession; a profession devoted to harnessing and modifying the three fundamental resources those humankinds has available for the creation of all technology: energy, materials and information. The overall goal of engineering education is to prepare students to practice engineering and in particular to deal with the forces and materials of nature. Thus, from the earliest days of engineering education, instructional laboratory classes have been an essential part of undergraduate and, graduates programs. Indeed, prior to the emphasis of engineering science, it could be said that the most engineering instruction took place in the laboratory.

The emphasis on laboratories has varied over the years. While much attention has been paid to curriculum and teaching methods, relatively little has been written about laboratory classes. One reason for the limited research on practicing laboratory classes may be a lack of consensus on the basic objectives of the laboratory experience. While there seem to be general that laboratories are necessary, little has been said about what they are expected to gain. In most papers about the practicing of laboratories, no expected outcomes or implicit knowledge are listed, even though it is not unusual for the author to state in the conclusion that the objectives of the course were met. An accepted set of fundamental objectives for laboratories would help engineering educators focus their efforts and evaluate the effectiveness of laboratory experiences or 'practical intelligence' [1].

Conventional approaches of assessment in engineering education focus mostly on explicit cognitive learning outcomes. Typically laboratory classes have been evaluated by assessing explicit knowledge and student perceptions of their laboratory experience. The authors have not been able to find any research undertaken to measure tacit knowledge or 'practical intelligence' acquired during laboratory work. Of course, workshop skills have been traditionally assessed by observing students performing their work and the quality of the artifacts created in the process. Practical intelligence is a critical part of these skills. Developing ways to include effective assessment of practical intelligence could be one way to overcome this difficulty.

\subsection{Practical intelligence in laboratory classes}

As outlined in [2], practical skills include the ability to acquire useful knowledge from experience, including "tacit knowledge" and unwritten know-how that is not explicitly taught and is often difficult to articulate, and to apply this knowledge to solving complex everyday problems. Complex everyday problems are distinguished

*Corresponding author : mhisam.daud@gmail.com 
from academic problems in that they are practical, must be solved with incomplete information, and often do not have a single correct answer...

Research on engineering practice confirms the importance of unwritten know-how or practical skill in everyday laboratory problems. Careful studies of engineering practice (e.g. [3]) have revealed that extensive technical knowledge is needed. Most of this unwritten knowledge is acquired after completing university courses and much of it is surprisingly basic. For example, engineers need to know the components and materials used in their discipline as practiced within a given firm, at least to the extent that they can recognize components and understand what they are used for. Much of this knowledge is so relatively simple on the one hand, and so specific to a particular firm or industry sector on the other hand, that it would not be appropriate to attempt to teach it in university engineering courses [3].

However, students need to appreciate the significance of this 'implicit' knowledge or 'practical intelligence' in engineering practice. However, since engineering courses restrict most assessment to explicit knowledge (the students have to write or speak to convey their knowledge), it is possible that the perceived relative value of practical intelligence and tacit knowledge may be reduced in the view of students. This might help to explain why employers often criticize the quality of the practical skills of engineering graduates [4].

Through their laboratory experience, the authors expect that students may acquire practical intelligence. It is possible they may learn enough for troubleshooting: to be able to detect and solve problems or diagnose faults in the equipment. This experience develops either intentionally or unintentionally and the authors hypothesize that informal learning is an important aspect of laboratory work.

\subsection{Assessing unintentional learning through diagnosing circuits' fault}

In current situation, complicated engineering process and systems need a systematic method of diagnosis. Thus, in recent years research efforts have shown that the technical problem due to faults can be detected in an early state by using diagnostic system. The diagnostic system must be equipped with the programming knowledge of how to relate faults and their effect to the operating state [5], but the programmers through their explicit knowledge develop that programming knowledge.

In term of human, the diagnostic engineer or technical person must be well self-enhancing knowledge of how to relate faults and the implications, which to learn from experience or gained by unintentional learning. This self-enhancing knowledge is developed through their working experience, and either explicit or tacit, but is expected mostly unintentional. By utilizing this knowledge, they will be expected to provide information of diagnostics for failure localization, planned preventive maintenance and service staff [6].
In order to increase critical thinking and awareness in terms of the equipment's fault, the need for training in fault diagnosis has been identified [5-8]. Thus, to become an engineer who will be able to diagnose the equipment faults, the engineering students have the opportunity to practice these qualities in their laboratory work. Hence the exercise on diagnosis of equipment fault is good practice for them. However, to achieve the performance in the exercise, pedagogical support was needed. Regarding to [9] in his experiential learning theory, four stages in experimental i.e. active experimentation, concrete experience, reflective observation and abstract conceptualization, should be incorporated in the practical exercise. When this practical exercise placed in this sequence, the stages form the experimental learning cycle, i.e. learning-bydoing [10-11].

Johnson [12] studied novice and expert troubleshooters extensively in order to understand their cognitive processes and skills. This and many other similar studies demonstrate that trouble-shooters make extensive use of tacit and implicit knowledge which has to be developed through experience. This is a powerful argument in support of the need for engineering students to practice and value the acquisition of practical intelligence.

The question is, do the students who gain experience during their laboratory classes possess a high level of practical intelligence acquired through informal learning which might allow them to diagnose the faults of equipment. Therefore, in this study, the authors examine informal learning through experience of laboratory work and the subsequent ability to diagnose equipment faults. Before the authors can achieve this goal, and given the well-known influence of assessment practices on student learning, the authors need to develop reliable ways to measure and assess the acquisition of practical intelligence. Psychologists, as shown above, have provided the required methods. All that remains is to develop specific testing instruments in the context of fault diagnosis.

\section{Research Methodologies}

\subsection{Purpose of research}

The aim of this research is to develop ways to measure changes in practical intelligence in order to assess unintentional learning or tacit knowledge, in engineering laboratory classes. In other words, the authors wish to develop ways to measure the experiential and "hands-on" component of learning laboratory classes.

The authors would also like to test the relationship between practical intelligence acquired in laboratory classes with the ability to complete circuit faults in laboratory equipment arrangements. 


\subsection{Research Design}

The study uses a quasi-experimental design of "Nonequivalent control group design" [13] with 2 x 2 factorial designs. The experiment design is as below:

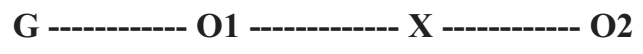

G - Experimental and control sample groups O1 - pre-test (using Automated Engineers Testing Kit)

$\mathrm{X}$ - Treatment (lab work for group experiments)

$\mathrm{O} 2$ - post-test (using Automated Engineers Testing Kit)

The testing instrument was used to test a number of students $(n=39)$ before and after they performed the relevant laboratory experiment tasks (named as experiment group). The pre-test and post-test contained the same circuits faults. A control group $(n=20)$ was recruited from a similar population students who were due to enroll in the same subject in the following semester. The control group completed the pre-test and post-test diagnosing circuits faults twice with a similar elapsed time between exposures, but without experiencing laboratory task. Seven domain experts such as laboratory demonstrators and electronics technicians provided reference scores as mentioned above

\subsection{Circuits' fault diagnosis instrument}

An instrument of circuits fault diagnosis is developed and known as 'Automated Engineers Testing Kits' is consisted of a partially completed circuit in which a battery provides power for a flash light. Participants were presented with the instrument and they were asked to diagnose why the light does not work and complete the necessary connections. Although the task seems very simple, almost trivial, it was necessary to design a task for which the students' scores would provide sufficient variation to provide statistically meaningful results. A substantially more challenging task may have resulted in performance being more related to random chance than acquired practical intelligence. Figure 1 shows the test kit for diagnosing the circuits' faults.

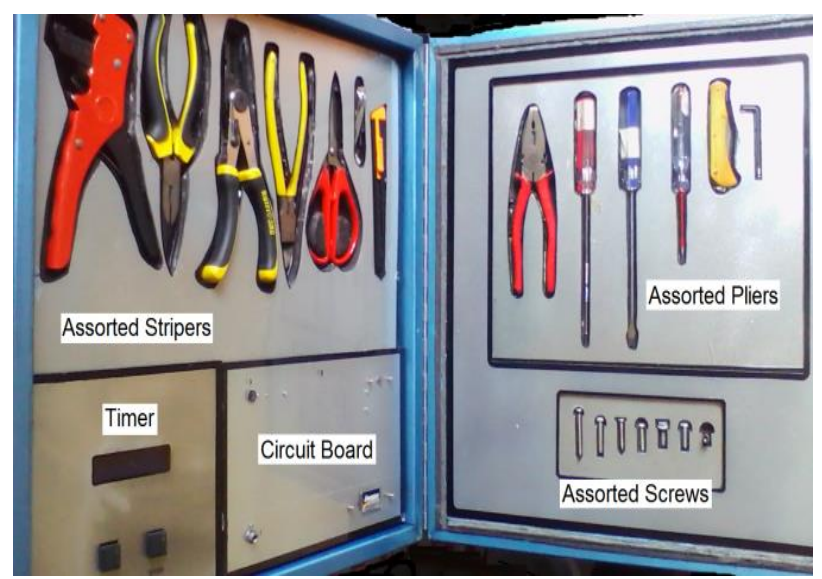

Figure 1: Automated Engineers Testing Kits

\subsection{Research Hypothesis}

The authors proposed a null hypothesis:

Hypothesis: The correlation between practical intelligence and the ability to diagnosis/repair basic circuits' faults is statistically insignificant.

If this hypothesis is proved to be false, the researcher can conclude that the acquisition of practical intelligence during the laboratory sessions significantly helps the participants to complete and diagnose faults in the circuit equipment used for the experiment.

This study is important to explore the relationship, if any, between Practical Intelligence score and ability to compete and repair the circuit's faults. The authors also need to explore the relationship, if any, between these measures and conventional assessment scores from lab reports, tests and examinations. Knowing that engineers need to be able to diagnose equipment faults and decide on repairs or modifications in their work, it would be useful to understand the kinds of assessment that could predict performance in this kind of work.

\subsection{Circuits' faults testing items}

There were 5 faults items (Table 1) in the circuit where the participants had to diagnose and repair it.

Table 1. The faults and diagnosis/repair tasks

\begin{tabular}{|c|c|c|}
\hline Location & Faults & Diagnosis/Repair task \\
\hline Point 2 & $\begin{array}{l}\text { Spring terminal } \\
\text { gripped the } \\
\text { insulation instead } \\
\text { of a wire metal. }\end{array}$ & $\begin{array}{l}\text { Detect the fault and let } \\
\text { the spring terminal grip } \\
\text { the metal wire }\end{array}$ \\
\hline Point 3 & $\begin{array}{l}\text { There was no } \\
\text { screw to connect } \\
\text { wires from point } \\
2 \text { and to point } 3\end{array}$ & $\begin{array}{l}\text { Choose an appropriate } \\
\text { screw from assorted } \\
\text { screws provided. }\end{array}$ \\
\hline Point 3 & $\begin{array}{l}\text { Tighten the screw } \\
\text { ensuring that the } \\
\text { wires are secured } \\
\text { together }\end{array}$ & $\begin{array}{l}\text { Choose an appropriate } \\
\text { tool from various tools } \\
\text { provided. Prevent the } \\
\text { wires from becoming } \\
\text { detached from the } \\
\text { screw terminal. }\end{array}$ \\
\hline $\begin{array}{l}\text { Point } 3 \\
\text { and } 4\end{array}$ & $\begin{array}{l}\text { Two unstripped } \\
\text { wires are too } \\
\text { short to connect } \\
\text { two terminals } \\
\text { required. }\end{array}$ & $\begin{array}{l}\text { Choose an appropriate } \\
\text { stripping tool from } \\
\text { various tools provided } \\
\text { and stripping the two } \\
\text { unstripped wires. }\end{array}$ \\
\hline $\begin{array}{l}\text { Point } 3 \\
\text { and } 4\end{array}$ & $\begin{array}{l}\text { Connect the two } \\
\text { short wires }\end{array}$ & $\begin{array}{l}\text { Choose an appropriate } \\
\text { way to connect the } \\
\text { wires }\end{array}$ \\
\hline $\begin{array}{l}\text { Entire } \\
\text { circuit }\end{array}$ & & $\begin{array}{l}\text { Measure the time to } \\
\text { complete repairs to the } \\
\text { circuit and for the light } \\
\text { to come ON. }\end{array}$ \\
\hline
\end{tabular}




\section{Analyses}

The main aim of this study is to find the value of practical intelligence acquired by correlating the score of diagnosing and repairing circuit faults for students and experts. In this analysis, the authors are interested in calculating the Pearson product-moments correlation between the pair of variables. For this, the authors made an analysis to test the possibility of correlation between the variables (students' scores and expert's scores).

\subsection{Analysis across samples}

The results of this investigation shows in Table 2 demonstrated that the original null hypothesis was false. These results demonstrated that the changes of practical intelligence (PI) can be measured by calculating the difference between students' ratings and the experts' ratings.

Table 2: Results of practical intelligence tests

\begin{tabular}{|c|c|c|c|c|}
\hline No & Analyses & $\begin{array}{l}\text { Mean } \\
\text { (close to } \\
\text { experts' } \\
\text { mean = } \\
0 \text { ) }\end{array}$ & $\begin{array}{l}\text { Std. } \\
\text { deviation }\end{array}$ & $\begin{array}{l}\text { Sig. (2 } \\
\text { tailed) }\end{array}$ \\
\hline 1 & $\begin{array}{l}\text { Pre-test } \\
\text { (Treatment } \\
\text { vs. } \\
\text { control) }\end{array}$ & $\begin{array}{l}113.3 \\
128.7\end{array}$ & $\begin{array}{l}35.34 \\
36.15\end{array}$ & $\mathrm{p}=0.078$ \\
\hline 2 & $\begin{array}{l}\text { Treatment } \\
\text { group } \\
\text { (pre-test vs. } \\
\text { post-test) }\end{array}$ & $\begin{array}{l}113.3 \\
68.3\end{array}$ & $\begin{array}{l}35.34 \\
18.95\end{array}$ & $\begin{array}{l}\mathrm{p}= \\
0.000^{* *}\end{array}$ \\
\hline 3 & $\begin{array}{l}\text { Control group } \\
\text { (Pre-test vs. } \\
\text { post-test) }\end{array}$ & $\begin{array}{l}128.7 \\
119.3 \\
\end{array}$ & $\begin{array}{l}36.15 \\
33.80 \\
\end{array}$ & $\mathrm{p}=0.076$ \\
\hline 4 & $\begin{array}{l}\text { Post-test } \\
\text { (Treatment } \\
\text { vs. } \\
\text { control) }\end{array}$ & $\begin{array}{l}68.3 \\
119.3\end{array}$ & $\begin{array}{l}18.95 \\
33.80\end{array}$ & $\begin{array}{l}\mathrm{p}= \\
0.000^{* *}\end{array}$ \\
\hline
\end{tabular}

The finding of the primary study showed that there is a statistically significant difference in Practical Intelligence scores (PI) for the treatment group measured before and after exposure to the laboratory class experience, compared to the control group where they did not participate in the laboratory. State differently, the treatment group participants acquired Practical Intelligence during the "hands-on" exposure while engaging with the laboratory experiments.

\section{Based on Table 2}

1. Both groups had the same level of initial PI as indicated by the pre-test scores.

2. There is a significant difference for treatment group, with an increment in the post-test close to experts' mean score. Data of standard deviation also shows that the spread of data point tends to be closed to the experts' score. The results suggest that, the treatment group is expected to acquire practical intelligence by performing laboratory tasks. Thus they were able to perform better in the post-test.

3. In contrast, for the control group, there is no significance difference between the pre-test and the post-test scores. Even though, there was an increment in the post-test score, the difference is not statistically significant. The results suggest that the intervening course work on other unrelated studies does not contribute toward PI improvement.

\subsection{Analysis between subgroup}

The comparison between testing conducted for this study by referring to experts mean score is summarized in Table 3 and illustrated in Figure 2. The participants in each group (categorized by the practical intelligence score) performed the diagnosis/repair equipment faults and were awarded a diagnosis score.

Table 3: Summary of test conducted

\begin{tabular}{|l|c|l|c|}
\hline Group & $\begin{array}{l}\text { Difference } \\
\text { in PI } \\
\text { means } \\
\text { score (\%) }\end{array}$ & Treatment & $\begin{array}{l}\text { Difference } \\
\text { in FD } \\
\text { means } \\
\text { score (\%) }\end{array}$ \\
\hline $\begin{array}{l}\text { Higher-post- } \\
\text { test } \\
\text { (treatment) }\end{array}$ & 19.69136 & $\begin{array}{l}\text { diagnose/ } \\
\text { repair } \\
\text { equipment } \\
\text { faults test }\end{array}$ & 13.84615 \\
\cline { 1 - 2 } $\begin{array}{l}\text { Lower-post- } \\
\text { test } \\
\text { (treatment) }\end{array}$ & 34.93827 & 25.38462 \\
\cline { 1 - 2 } $\begin{array}{l}\text { Post-test } \\
\text { (control) }\end{array}$ & 44.25926 & & 44.61538 \\
\cline { 1 - 2 } $\begin{array}{l}\text { Experts (for } \\
\text { comparison) }\end{array}$ & 0 & & 0 \\
\hline
\end{tabular}

\section{Comparison of mean score for PI and FD tests}

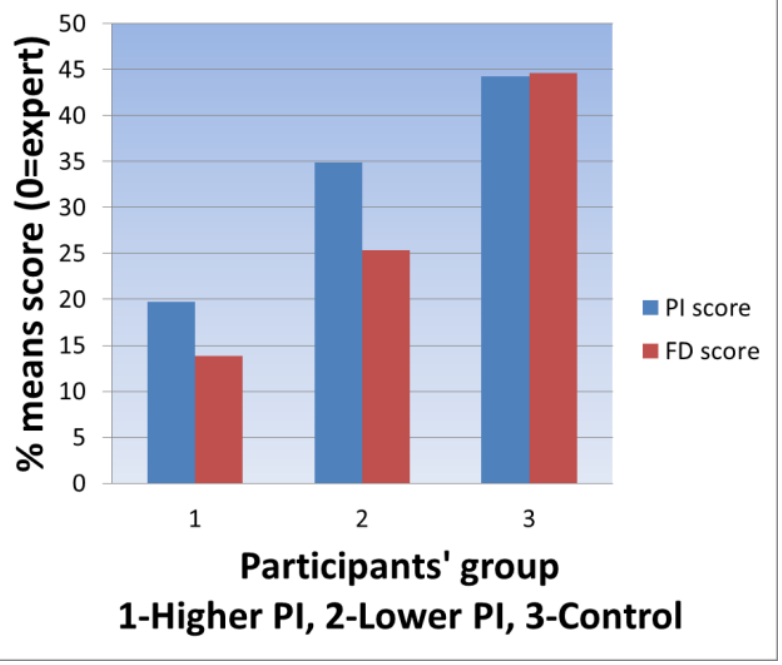

Figure 2. Comparison of the mean for each group with experts

Participants in the higher post-test (treatment) group have the lowest difference in practical intelligence score (mean 19.7\%) and awarded 13.8\% diagnosis/repair mean score. The results revealed that the participants in this group performed well in the practical intelligence test 
even though are not correlated with the fault diagnosis/repair test. Practical intelligence that they acquire during the laboratory experiments helped them to diagnose and repair the equipment faults, able to use an appropriate tool and complete the exercise promptly.

For the other two groups, the means score for practical intelligence test and diagnosis/repair test are higher than the first group. Even though there are no significant correlation, the authors found that the participants were able to do the diagnose/repair tasks and use the tools although some of them exceed the time given.

\subsection{Analysis entire samples}

The results of the testing for the entire samples are summarized in the section 6.5.2. There is a correlation between the combination of the post-test scores and diagnosis/repair score, with the value of correlation is 0.752 , while the 2-tailed $p$-value is 0.001 . The results show that there is a correlation between the practical intelligence scores and diagnosis/repair scores. The results of the diagnosis/repair test provide further clarification of the relationship between Practical Intelligence and the ability to diagnose/repair equipment faults. Figure 5 deficits the relationship between the Practical Intelligence score for the 3 groups of participants in the fault diagnosis study with their ability to repair and diagnose equipment faults.

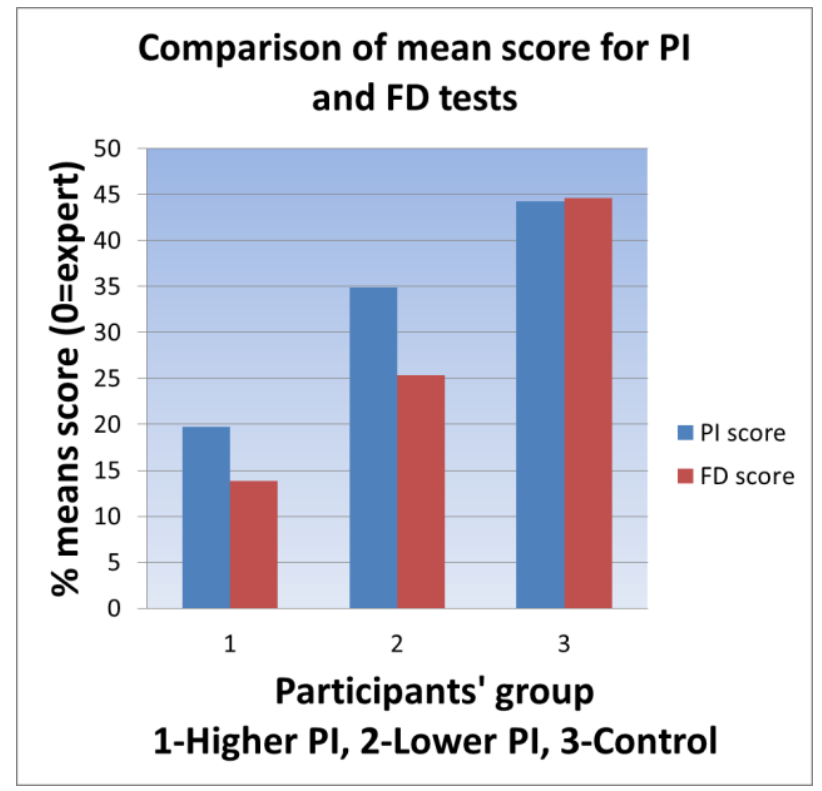

Figure 5: Relationship between the Practical Intelligence score for the 3 groups of participants

The results show that the higher PI group gained lowest difference score in the diagnosis/repair test (slightly parallel in practical intelligence). The post control group gained lesser, but their score is slightly proportional to the practical intelligence. For lower PI group, their score is scattered. The result for this separate analysis shows there is no obvious correlation.

Further research on the relationship between Practical Intelligence vs. ability of diagnosing equipment faults showed a novel relationship (Figure 3). The score of the fault diagnosis test is proportional to the practical intelligence score, the higher the practical intelligence score, the higher the fault diagnosis score. Therefore the results suggest that PI scores predict ability to diagnose equipment faults in similar laboratory equipment.

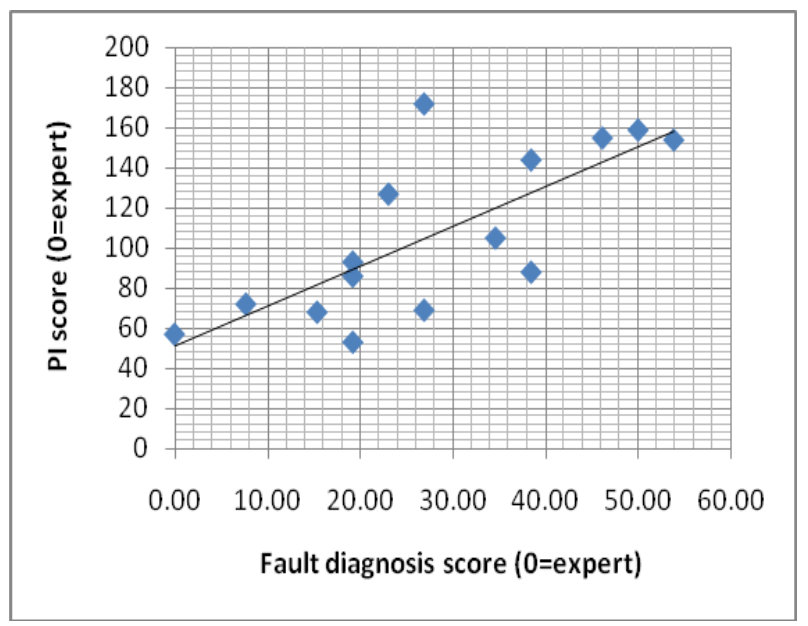

Figure 3: Results of practical intelligence (PI) proportional to fault diagnosis

\section{Discussions}

Constructing a survey instrument was not an easy exercise in the first instance. The authors were surprised by the relative lack of practical knowledge demonstrated by the students and it was not easy to construct a test which would result in meaningful scores. The authors learned through this research that a close examination and analysis of actual student behaviour in the laboratory is essential, over an extended period of time [14]. This provides significant insights into the learning by students. Through conversations with the students, one can begin to appreciate how learners are constructing new understandings based on their pre-existing knowledge [15]. An understanding of Zygotsky's notion of zones of proximal development was also useful [16] : students can only learn something if they have sufficient pre-existing knowledge on which to construct the required new knowledge.

It is possible that the author may be able to alter student learning behavior by including practical intelligence tests in assessment processes. It is well known that assessment practice drives student learning behavior [10]. The testing may motivate students to acquire the ability to learn practical intelligence which could ultimately make them more effective as practicing engineers. It is possible that they will learn to value the practical intelligence and possibly relate better to tradespeople and technicians on whom engineers need to rely to achieve practical results from their work.

Of course, the actual PI measurement instruments used in this research can only be applied in the context of similar laboratory classes with the same equipment. While the same problem situations might be applicable 
in other institutions, it is essential to use photographs and diagrams of the actual equipment used by the students.

However, before we can apply this research with confidence, we need many more similar investigations with large numbers of student participants. This paper has outlined the approach we followed. Once the concepts are understood and the necessary detailed observations of student behaviour have been completed, it is possible to readily create an appropriate survey instrument in order to collect data and, hopefully, later, to use the same instrument as a student assessment tool. The same approach can be applied in the context of our remote laboratories. In our situation, we allow the students to have access to the physical equipment. We introduce them to the equipment before they start, both in lectures and tutorials.

Creating a practical intelligence instrument, as described, would require extensive detailed observation of students, both in laboratory working alongside the actual equipment, and remotely operating the equipment somewhere else. However, such an instrument would provide a useful alternate means to assess tacit and implicit learning, and might be a better predictor of troubleshooting performance than conventional written assessments that currently dominate education practice.

\section{Conclusions}

For this research, the authors hypothesized that practical intelligence measured in the context of constructing simple circuits used for laboratory experiments will be correlated with performance in real constructing tasks on similar complicated electrical circuits. The results show the correlations between the level of practical intelligence and the ability to construct the circuits. The results proved the previous research that experience or academically called 'practical intelligence' in the field of engineering (diagnosing circuit faults) can be measured through comparing experience to the experts. Through some repeated hands-on exercises, the level of students' practical intelligence continuously developed. This is tested and by using 'Automated Engineers Testing Kits' where level of practical intelligence of students' is proved can be assessed.

The results demonstrate that the author can devise effective ways to measure changes on practical intelligence acquired in order to assess unintentional learning from laboratory experiences. This would provide a third means to evaluate engineering laboratory class experiences, beyond the established methods of comparing student performance in explicit assessment tasks (e.g. reports, tests) and measurement of student perceptions of their laboratory experience. The study on fault diagnosis provided a clear relationship demonstrating the possibility that practical intelligence predicts fault diagnosis ability.

The author would like to acknowledge the support from the Fundamental Research Grant Scheme (FRGS) under a grant number of FRGS/1/2014/ICT06/UNIMAP/ 9003-00442 from the Ministry of Higher Education Malaysia.

\section{References}

1. L.D. Feisal, A.J. Rosa. Journal of Engineering Education, 94, 1 (2005)

2. R.J. Sternberg. College and University, 82, 1 (2006)

3. J.P. Trevelyan. Journal of Engineering Education, 96, 3 (2007)

4. F.V. Christiansen, C. Rump European Journal of Engineering Education, 32, 4 (2007)

5. R. Isermann, Automatica, 29, 4 (1993)

6. L. Monostori, Robotics and Computer-Integrated Manufacturing. 4, 3 (1988).

7. S.D. Johnson. Journal of Industrial Teacher Education, 26, 3 (1989)

8. Z.B. Razali, J.P.Trevelyan, Annual Conference of the Australasian Association for Engineering Education, Queensland (2008).

9. D.A. Kolb Experiential Learning: Experience as the source of learning and development... New Jersey: Englewood Cliffs, NJ: Prentice Hall (1984)

10. G. Gibbs. Research, Teaching and Learning in Higher Education S. B and B. S (1988)

11. K. Garmer, L. Sperling. Applied Ergonomics. 33, 1 (2002).

12. D. Halpern. Thought and knowledge: An introduction to critical thinking. Hillsdale, NJ: Lawrence Erlbaum Associates (1989).

13. S. Issac, M. Michael, Research Design in Education. New Jersey: Englewood Cliffs, NJ: Prentice Hall (1963)

14. Z.B. Razali, J.P.Trevelyan. Jurnal Teknologi (Social Science) UTM, 64(1) (2013) p11-16.

15. J.D. Bransford, A.L. Brown, R.R. Cocking, M.S. Donovan \& J.W. Pellegrino (Eds.). (2000). How People Learn: Brain, Mind, Experience and School. Washington DC, USA: National Academy Press.

16. A.L. Brown, D. Ash, M. Rutherford, K. Nakagawa, A. Gordon \& J.C. Campione (1993). Distributed expertise in the classroom. In G. Salomon (Ed.), Distributed cognitions: psychological and educational considerations (pp. 188-228): Cambridge University Press. 